und andere essigsaure Metallsalze schäumen stark. Essigsaure Eisenoxydlösung schäumt auch nach der Behandlung unter der Luftpumpe, wodurch ihr viele absorbirte Luft entzogen wird. Aehnlich verhält sich die Lösung des citronensauren Eisenoxyduts.

Die Eigenschaft zu schäumen ist vom specifischen Gewichte durchaus unabhängig.

Der Schaum auf der Oberfläche einer gefärbten Flüssigkeit zeigt fast stets eine hellere Färbung, als die Flüssigkeit selbst. Eine von den wenigen Ausnahmen, bei denen der Schaum anders gefärbt erscheint, als die Flüssigkeit, ist die dunkelrothe wässerige Lösung der Cochenille, die durch Schütteln einen starken blassbläulich-purpurnen S'chaum erzeugt. (Lond. Phil. Mag. Pharm.Journ. and Trans. Sept.1858. p.194ff.) Hendess.

\title{
Ueber die Verbreitung des Fluors
}

hat Nicklès, Professor an der Facultät der Wissenschaften zu Nancy, eine umfangreiche und sehr gelehrte Abhandlung verötfentlicht, aus der sich folgende Șchlussforderungen ziehen lassen:

1) Das Fluor findet sich in sehr kleinen Mengen im Blute; es findet sich

2) im Urine,

$3)$ in den Knochen, aber weit geringer als man bisher nnnahm. Nach Berzelius enthalten $100 \mathrm{Grm}$. kalkartige Materie der Knochen 3 Grm. Fluorcalcium, wógegen Nicklès kaum 0,05 Grm. aus 1 Kilogrm. erhalten konnte.

4) Die Quellen, welche dem thierischen Organismus das nöthige Fluor zuführen, sind:

a) die Trinkwässer,

b) die Pflanzensubstanzen. Beide enthalten indessen das Fluor in so winzigen Mengen, dass man, um nur Spuren davon zu erhalten, mindestens 1 Kilogramm Asche und den Rückstand von einigen Tausend Liter Wasser in Arbeit nehmen muss;

c) alich zufällig kann der Organismus Fluor aufnehmen, und zwar aus den Mineralwässern, welche alle, im Vergleich zu den Trinkwässern, grosse Mengen von Fluorverbindungen enthalten;

d) dieser Umstand könnte vielleicht die Wirkung einiger schwach mineralischer Mineralwässer erklären, wie der von Plombières, Mont d'Or, Sultzbad ete. 
5) Das bei Paris geschöpfte Seine-Wasser enthält wenig Fluorverbindungen.

6) Eines der an Fluorverbindungen reichsten Flusswässer Frankreichs ist das Wasser der Somme bei Amiens.

7) Die verschiedenen Mineralwiisser sind nicht gleich reich an Fluorverbindungen. Die reichhaltigsten der von Prof. $\mathrm{Nick}$ lès untersuchten sind die von Contrexeville, Antogast,' Rippoldsau, Geilnau. 1 Liter dieser Wïsser genügt, um unzweideutige Spuren von Fluor $\mathrm{zu}$ erhalten. Dagegen liefert:

8) das Wasser des atlantischen Meeres erst eine nachweisbare Spur Fluor in 300 Liter.

9) Als Norm lässt sich annehmen: Fluorcalcium findet sich in allen Gewässern, welche doppelt-kohlensauren Kalk enthalten; ebenso findet sich Fluor in den durch Absatz gebildeten Mineralien.

Nicklès macht noch besonders darauf aufmerksam, dass bei Untersuchungen auf Fluor besondere Rücksicht auf die Schwefelsäure zu nehmen ist. Sie muss vollständig frei von Fluorwasserstoffsäure sein und darf nicht in Glasgefässen aufbewahrt werden. (Journ. de Pharm. et de Chim. Septbr. 1858. p. 185 ff.)

Hendess.

\section{Ueber die Verbindung des Schwefels mit Jod.}

Die Verbindung des Schwefels mit Jod, welche als äusserliches Mittel in Gebrauch ist, hat ihre Unbequemlichkeiten. Sie röthet die Haut, und zum innern Gebrauch hat man dieselbe aufgegeben. L. Vezu hat eine andere Bereitungsweise vorgeschlagen, wodurch eine innigere Verbindung des Jods mit dem Schwefel bezweckt wird. Er räth nämlich, jedes besonders, den Sclswefel und das Jod, in Mandelöl zu lösen, nümlich 8,25 Gran Schwefel und 15 Gran Mandelöl werden zusammengemischt in einem Glaskölbchen und so lange erwärmt, bis der Schwefel aufgelöst ist. In einem andern Kölbchen werden $0,80 \mathrm{Gr}$. Jod in $15 \mathrm{Gr}$. Mandelöl gelöst, nun beide Lösungen vermischt, därauf erwärmt und nach $\operatorname{dem} \mathrm{Ab}$ kühlen filtrirt. So bereitet, bernerkt man keinen 'Jodgeruch und färbt eine Kleister-Aufösung nicht violett. In Aether löst sich die Verbindung vollständig auf, ohne dass der Schwefel zurückbleibt, und auch diese Lösung färbt die Kleisterlösung nicht.

Durch wiederholtes Auswaschen mit Alkohol wird kein Jod aufgelöst, und kann man dieses Präparat ohne 